\title{
Mulheres Terena: das universidades para as terras de retomadas da Aldeia Buriti em busca do direito coletivo: terra mãe
}

\author{
Devane Alves Gabriel*
}

Sou Terena. Me chamo Devane Alves Gabriel, pertencente a etnia Terena de tronco linguístico Aruak. Nascida e educada em minha terra de origem, aldeia Indígena Buriti no Município de Dois Irmãos do Buriti, MS. Atualmente atuo como professora na Escola Estadual Natividade Alcântara Marques, após ter me qualificado para a carreira de professor. Em minha infância, cursei as séries iniciais do ensino fundamental na escola Municipal Indígena Alexina Rosa Figueiredo localizada nesta aldeia mas tendo que concluir o final do ensino em Campo Grande, a capital do estado de Mato Grosso do Sul, na escola do não indígena: Escola Municipal Coronel Sebastião Lima.

Desloquei-me para a cidade nesse período de estudos pelo fato de ser a filha mais velha e sempre pensei em melhorar a condição de vida de meus pais, no entanto, decidi-me a ir morar com minha tia Luiza em Campo Grande. Minha tia que a considero como uma segunda mãe por tudo que fez e ensinou-me, mas o motivo maior pela escolha de ir morar na cidade foi devido a necessidade em trabalhar para me auto sustentar e assim poder usufruir de materiais necessários e a ajudar meus irmãos dependentes de meus pais dos quais até o momento contribuo para seu sustento.

Morei em Campo Grande dois anos na qual iniciei o ensino médio na Escola Estadual Amélio Carvalho Baís, CG, MS ,mas não conclui pelo fato de não conseguir me adaptar a outros costumes totalmente diferente do meu povo e neste mesmo ano de 2005 decidi voltar para minha aldeia e concluir meus estudos na escola indígena. Ao retornar para a aldeia, logo me casei aos 19 anos e tive meu filho, no inicio do meu

* Acadêmica do Curso de História da Universidade Católica Dom Bosco. E-mail: devanegabriel@hotmail.com 
matrimônio tive que trancar os estudos para dedicar-me aos cuidados de meu filho recém-nascido.

Retornei os meus estudos no ano de 2010 podendo assim concluir o ensino médio, porém novamente tive que dar mais um tempo pelo fato de não ter condição financeira para me manter na universidade, porém, não desanimei. O interesse em cursar o ensino superior em História se deve ao fato de ser uma mulher envolvida com os acontecimentos no interior da comunidade indígena. E também procuro sempre estar em todos os nossos movimentos de interesses coletivos, o que me possibilitou a me aperfeiçoar nos conhecimentos tradicionais. Percebi então que a Universidade me traria subsídios para melhor compreensão da cultura e tudo que envolve as populações nativas. Em 2012 prestei o vestibular na Universidade Católica Dom Bosco (UCDB) e fui aprovada e a partir deste ano, iniciei a carreira acadêmica nesta instituição.

No mesmo ano foi aprovado nesta instituição a bolsa de $100 \%$ para acadêmicos indígenas, com as articulações de nosso povo terena do estado em a parceria com o projeto Rede de Saberes. O projeto Rede de Saberes visa auxiliar os acadêmicos indígenas e sua permanência na universidade, sendo este através de monitorias, auxílio ao acadêmico na construção de trabalhos como artigos científicos, monografias, trabalhos em banners. E por fim, custeando a sua participação em eventos fora da instituição, tal como: passagem, hospedagem, alimentação entre outros recursos.

O acadêmico, ao iniciar sua carreira estudantil na universidade é apoiado por toda a comunidade indígena, sendo que, esta comunidade de origem aguarda pelo seu retorno contribuindo com subsídios de conhecimentos científicos adquiridos na academia para serem trabalhados juntos com a comunidade. Sendo este o objetivo maior em sua ida às instituições, para as contribuições ao regressar e assim trabalharem em conjunto com as nossas "lideranças tradicionais". Nós enquanto acadêmicos, somos postos como a nova liderança letrados e aptos a defender a comunidade e seus direitos, independente do tempo e espaço, o compromisso é esse: a defesa de nossos direitos.

A presença dos estudantes universitários nas reuniões ocorridas no interior da aldeia tem sido de suma importância, pois, participamos ouvindo nossos líderes, nossos velhos troncos, nossos xamãs e com isso nos apropriamos de saberes vindo de nossa tradição, diante disso sentimo-nos mais fortalecidos para o enfrentamento do racismo muito presente. $\mathrm{O}$ preconceito da qual sofremos fora de nosso habitat, principalmente nas academias e assim caminhamos, aprendendo com eles que nos conduz nos fortalecendo 
intensamente em superar os desafios impostos pela sociedade não-indígena, os purútuye.

A academia a nós contribuiu com a compreensão maior do ser " indígena", a valorizar as histórias do meu povo e através das disciplinas cursadas durante os anos, principalmente as da área especifica, muito me ensinou. Os estudos sobre as histórias e organização de outros povos incluindo a história da arte da qual o professor expõe os valores dos diversos povos distintos e de estilo e modo de viver diferente, foi então que me dei conta da riqueza de nossa cultura. A pintura e os artesanatos indígenas são ricas, não enquanto material mas a de uma riqueza cultural única. Diante disso comecei a valorizar muito mais as histórias orais contadas pelo meu avô Trindade Alves (in memória). Meu avô foi um dos principais incentivadores dos meus estudos, graças ao seu conhecimento transmitido através da oralidade e de ter convivido com ele até os meus 25 anos de idade.

Atualmente transmito ao meu filho o valor dos anciãos e o quanto ainda temos que aprender com eles. Além disso, os troncos velhos também me auxilia nesse processo de busca do conhecimento da história de meu povo. Neste cenário estão também as professoras das quais eu convivo: Ana Sueli Fermino e Eva Fernandes, com quem sempre dialogo e estão sempre dispostas a me ajudarem a perceber a difícil tarefa de quebrar a barreira da participação da mulher nos movimentos de nossa comunidade, na luta pelos nossos direitos e a aceitação dos homens nestes espaços que lentamente vem sendo ocupados pelas mulheres.

Veriana Alves (minha avó), também é uma das minhas maiores referencias, uma das principais responsáveis na construção do Trabalho de Conclusão de Curso (TCC) de História. Ela foi a peça fundamental na narração de como era antes e o que mudou referente aos papéis exercidos pelas mulheres no contexto e universo indígena após a busca do ensino superior para somar com a comunidade de origem.

O interesse em escrever sobre a importância das mulheres Terena da aldeia Buriti na retomada de nosso território tradicional, tem sido por fazer parte deste povo e estar presente em todas os momentos das retomadas ocorridas entre o ano 2000 a 2013, principalmente por pertencer ao território onde ocorreu uma das piores ações policiais em 2013, tido como um verdadeiro cenário de guerra.

No entanto quando as primeira mulheres que decidiram sair da comunidade para ingressarem na universidade, sofreram muitas discriminações em forma de calúnias por parte da própria comunidade e as vezes pelos próprios familiares. Quando casadas, recebiam as críticas dos familiares e seus esposos 
dizendo: "lugar de mulher é em casa lavando roupa, cuidando do marido que está na roça trabalhando". E isso não fica tão distante da realidade do que vivemos ainda hoje, encontramos maridos que não deixam as esposas trabalharem ou estudarem por medo talvez de elas construírem uma nova visão de valores e direitos da mulher em uma sociedade.

Muitas vezes, a visão da mulher que permeou pelas academias, sempre retornam com amplas reflexões de seu papel e lugar na sociedade indígena, espaços de decisões principalmente, o de exclusividade masculina no âmbito de suas resoluções. Hoje, elas participam nas decisões. As mulheres podem muito bem resolver os problemas da casa, não é mais somente responsabilidade do marido colocar a comida na mesa. Ouso aqui relatar uma experiência própria de quando eu iniciei a vida acadêmica, já era casada e na época meu filho tinha estava com quatro anos de idade e eu ouvi do meu pai dizendo: "lugar de mulher é em casa cuidando do marido e acabou" e ainda disse "onde já se viu, mulher casada sair de casa e deixar filho pequeno pra estudar depois de casada!".

Desta forma percebemos a difícil tarefa feminina por ser mulher, provar e mostrar a sociedade seus valores e capacidades mesmo contrariadas no âmbito familiar e étnico. Posso afirmar categoricamente que ser mãe, esposa e acadêmica não é uma tarefa fácil! Se não encontrarmos o apoio e compreensão familiar não conseguimos avançar e nem tão pouco concluir os estudos. São vários os "desafios" a respeito dessa nova mulher que surge.

Há momentos em que precisamos nos ausentar de casa e deixar os filhos por mais de uma semana devido os compromissos acadêmicos, mas quando realmente estamos decididas querer lutar pelas conquistas de nosso direito, temos que estar preparadas para os grandes desafios, inclusive a ausência da família. Porém, acreditamos no reconhecimento, da qual conseguimos expor, somos tão capazes como muitos homens e pessoas não indígenas que vivem nos discriminando e nos inferiorizando.

Quanto à nossa participação, as mulheres nas terras de retomadas (terra declaradas indígenas, em processo de homologação), esta tem sido uma conquista árdua e desafiadora. Falo por experiência própria, que na primeira retomada no ano de 2000, segundo relato de meu pai (Jair Gabriel, 48 anos), houve uma inexpressiva participação das mulheres chegando no máximo umas 10 mulheres.

Na época, essas mulheres foram chamadas de "ousadas" por não respeitarem as decisões de seus esposos que sempre diziam que as mulheres não podiam participar das retomadas pelo fato de ser um local de risco para elas. Os homens diziam querer proteger as mulheres do perigo. Pois poderiam sair às presas e as mulheres não iriam conseguir acompanhá-los no desespero. 
Mas com a insistência da mulher em participar das reuniões da comunidade, sempre teimarem quando os homens diziam para elas ficarem no âmbito familiar em casa. Quando percebidas, elas já estavam na frente dos movimentos. Desta forma as Terena da aldeia Buriti foram conquistando seus espaços e tendo voz na comunidade. Ao perceberem essa insistência, os homens decidiram a começar a ceder espaço para essas mulheres ditas ousadas e que mostravam interesse na luta ao direito territorial.

No ano de 2013 ocorreu na aldeia Buriti, uma das piores ações policiais da época, sendo que este aconteceu durante a luta pela conquista de nosso território. $\mathrm{O}$ momento era delicado, pois precisávamos estar aqui presentes junto do nosso povo e com isso precisávamos conciliar a ida para a faculdade.

A preocupação estava em torno de: como vou deixar meu filho, meu esposo, meus pais e parentes aqui na aldeia e ir para a cidade correr o risco de sofrer qualquer atentado e deixar os meus familiares ainda mais preocupados do que já estão, pelo fato de eles saberem o perigo que estamos correndo ao sair da comunidade?

Parecia nada progredir e que tudo estava conspirando contra nós. A aflição me tomava conta, na dúvida, pensei em trancar o curso ou continuar pois estava ciente que meu povo estava a minha espera e que precisam dos meus conhecimentos adquiridos na academia para melhor compreensão de alguns assuntos da comunidade.

Fui educada a valorizar os anciões presentes em minha comunidade e a partir deles pude conhecer as lutas vivenciadas na aldeia, a língua que, no entanto era muito falada, os mitos contados, as memórias de nossos velhos muitos nos revelam. Enquanto filha, sempre observei o papel das mulheres na comunidade, a minha mãe, minhas tias que moravam próximas de minha casa e ao fazer essa observação percebi que todos os dias repetiam as mesmas coisas, como os afazeres domésticos e que aparentava ser uma "obrigação" como esposa e mulher, no qual se limitava em suas próprias residências aos afazeres domésticos.

A colheita do plantio na lavoura e a sua comercialização eram os principais assuntos tidos no momento de conversas entre marido e esposa, ou, homem e mulher, sempre em volta da fogueira na hora do mate (momento em que os mais velhos sentam juntos toma o chimarrão enquanto trocam informações). O assunto em pauta centrava-se sempre em torno ao comportamento dos filhos e como foi feito a comercialização e o consumo dos produtos colhidos na lavoura.

Ainda hoje faço essas observações, mas percebo as várias mudanças ocorridas no dia-a-dia das mulheres Terenas da aldeia Buriti com a ida destas 
para as universidades e os espaços que ocupam hoje na comunidade e até mesmo fora da aldeia. Para melhor compreensão deste processo de valorização da presença feminina nos campos de discussão e decisão de acontecimentos envolvendo a comunidade, foi realizado uma pesquisa com as mulheres anfitriãs. O trabalho foi direcionado para buscar respostas desta construção na valoração da mulher em minha comunidade.

O primeiro passo foi saber das próprias mulheres, o que elas pensavam, a respeito das limitações as que eram expostas, como por exemplo, os afazeres cotidianos domésticos e a ausência de suas vozes. Percebe-se que a ideia de ser uma "obrigação" destas em ter que cuidar dos filhos, das lavouras e direcionar a palavra ao marido sobre esses assuntos, esta era uma orientação repassada de mãe para filha.

Algumas diziam que filha mulher tinha que aprender cuidar dos afazeres domésticos e quando casada, saber cuidar do marido e dos filhos. Ao marido cabia a busca de alimentos, trabalhar para manter a família, desta forma, desde a infância era treinados para papéis distintos, sendo os trabalhos destinados a cada sexo. No entanto, existia certo limite de serviços distribuídos a cada um, também era obrigação feminina buscarem lenha na roça quando em falta na casa e a colher frutos silvestres da época.

As mulheres que iniciaram a busca por esta mudança sofreram muitos tipos de calúnias, principalmente se casada, calúnias estas sofridas dos próprios familiares e ainda hoje presente de certa forma, como já dito anteriormente. Apesar dos maus comentários, elas hoje conquistaram o apoio da comunidade e de seus esposos na busca da conquista deste espaço, uma conquista tida lentamente, com diálogo, reflexões e enfrentamento.

Com este avanço, atualmente somos muito mais ouvidas, porém percebemos ainda existir certo receio de algumas mulheres em falar nas reuniões da comunidade. Pois são nesse espaço, tido campo espaço político, pois envolve discussões e decisões, onde a oratória é de exclusividade masculina e, no entanto, as mulheres vêm conquistando aos poucos.

Atualmente existe um número expressivo de mulheres ocupando vários cargos no serviço público na comunidade, o que tem as colocado nos espaços de discussões. No mais, a quantidade de mulheres indo a busca do ensino superior também tem aumentado expressivamente, todas com um mesmo objetivo: concluir o ensino superior e voltar para a nossa comunidade para cumprir com sua nova tarefa, a somar ainda mais com os esposos na luta da conquista de nossos direitos.

Portanto, aquelas mulheres que foram educadas apenas para os afazeres domésticos, hoje pensam em retornarem aos bancos escolares e ainda ter uma 
chance de ao menos concluir o ensino médio ou até mesmo a vir a cursar o ensino superior. Este novo cenário em que se encontram essas novas mulheres, tem sido aceito pela comunidade, pelos familiares, e, principalmente pelos maridos.

O acolhimento familiar proporcionou as idas e vindas delas da aldeia para a universidade, pois entende-se que as conquistas dessas mulheres não trará um benefício individual, a conquista está em torno de muito além de um simples diploma universitário. A conquista esperada pela comunidade indígena, e em especial a aldeia Buriti, no que se refere este trabalho, está em torno de uma conquista coletiva, no âmbito cultural: dominar os códigos do outro - o não indígena, a linguagem e os conhecimentos científicos como forma política de sobrevivência e lutas pelo direito dos povos nativos, a que pertence esta comunidade Terena. Daí, a grande contribuição das mulheres Terena.

Recebido em 15 de julho de 2015

Aprovado para publicação em 10 de setembro de 2015 